\title{
Pengaruh Perubahan Curah Hujan dan Perubahan Tutupan Lahan terhadap Bencana Longsor berdasarkan Analisis Spasial
}

\section{Hana Syarifah Firdaus*}

Prodi Teknik Perencanaan Wilayah \& Kota, Fakultas Teknik, Universitas Islam Bandung, Indonesia.

*hana.s.firdaus@gmail.com

Abstract. West Bandung Regency is one of the areas that has the potential for landslides in Indonesia. The occurrence of landslides in West Bandung Regency is the most common type of disaster, with a percentage of 68\% in West Bandung Regency in 2008 - 2016 compared to other types of disasters. This research uses a quantitative approach spatially. The purpose of this study was to examine the level of landslides in the West Bandung Regency from the influence of changes in rainfall and land cover changes based on spatial analysis. The method of data collection is done by the method of secondary data collection. The analytical methods used include land cover classification analysis in 2018 - 2020 and analysis of the level of landslide disasters from the existing conditions of landslides in 2018 - 2020. From the results of research using overlay analysis, in 2018 the disaster level landslides with a low level of $31,309.90 \mathrm{Ha}$ or $24.47 \%$ and a medium level of $96,660.06 \mathrm{Ha}$ or $75.53 \%$ with a total of 150 landslides in 61 villages. In 2019, the level of landslides was low at 31,752.25 Ha or $24.84 \%$ and the medium level was $96,091.22 \mathrm{Ha}$ or $75.16 \%$ with 152 landslides in 53 villages. In 2020 the landslide disaster level has a low level of $15,280.42 \mathrm{Ha}$ or $11.94 \%$, a medium level of $108,381.46 \mathrm{Ha}$ or $84.69 \%$, and a high level of $4,308.11 \mathrm{Ha}$ or $3.37 \%$ with the number of landslides as many as 144 times in 67 villages.

Keywords: impact, change, rainfall, land cover, landslide disaster, spatial.

Abstrak. Kabupaten Bandung Barat menjadi salah satu wilayah yang memliki potensi bencana longsor di Indonesia. Kejadian bencana longsor di Kabupaten Bandung Barat merupakan jenis bencana yang paling banyak terjadi yaitu dengan presentase sebesar 68\% di Kabupaten Bandung Barat pada Tahun 2008 - Tahun 2016 dibandingkan dengan jenis bencana lainnya. Penelitian ini menggunakan pendekatan kuantitatif secara spasial. Tujuan dalam penelitian ini untuk mengkaji tingkat bencana longsor di wilayah Kabupaten Bandung Barat dari pengaruh perubahan curah hujan dan perubahan tutupan lahan berdasarkan analisis spasial. Metode pengumpulan data yang dilakukan dengan metode pengumpulan data sekunder. Metode analisis yang digunakan diantaranya analisis klasifikasi tutupan lahan untuk melihat tutupan lahan pada Tahun 2018 - Tahun 2020 dan analisis tingkat bencana longsor dari kondisi eksisting bencana longsor pada Tahun 2018 - Tahun 2020. Dari hasil penelitian menggunakan teknik analisis overlay didapatkan bahwa pada Tahun 2018 tingkat bencana longsor dengan tingkat rendah sebesar 31.309,90 Ha atau 24,47\% dan tingkat sedang sebesar $96.660,06 \mathrm{Ha}$ atau $75,53 \%$ dengan jumlah longsor sebanyak 150 kali pada 61 desa. Pada Tahun 2019 tingkat bencana longsor rendah sebesar $31.752,25 \mathrm{Ha}$ atau $24,84 \%$ dan tingkat sedang sebesar $96.091,22 \mathrm{Ha}$ atau $75,16 \%$ dengan jumlah longsor sebanyak 152 kali pada 53 desa. Pada Tahun 2020 tingkat bencana longsor memiliki tingkat rendah sebesar 15.280,42 Ha atau 11,94\%, tingkat sedang sebesar 108.381,46 Ha atau 84,69\%, dan tingkat tinggi sebesar 4.308,11 Ha atau 3,37\% dengan jumlah longsor sebanyak 144 kali pada 67 desa.

Kata Kunci: pengaruh, perubahan, curah hujan, tutupan lahan, bencana longsor, spasial. 


\section{A. Pendahuluan}

Kabupaten Bandung Barat menjadi salah satu wilayah yang memliki potensi bencana longsor di Indonesia. Kejadian bencana longsor di Kabupaten Bandung Barat merupakan jenis bencana yang paling banyak terjadi yaitu dengan presentase sebesar $68 \%$ di Kabupaten Bandung Barat pada Tahun 2008 - Tahun 2016 dibandingkan dengan jenis bencana lainnya. Berdasarkan Dokumen Kajian Risiko Bencana Kabupaten Bandung Barat Tahun 2017- Tahun 2021, jumlah kejadian bencana alam yang terjadi di Bandung Barat paling banyak terjadi pada jenis bencana tanah longsor yaitu sebanyak 52 kali terjadi dalam kurun waktu Tahun 2008- Tahun 2016. Korban bencana longsor selama Tahun 2008- Tahun 2016 di Kabupaten Bandung Barat terdapat 31 orang meninggal, 5 orang hilang, 63 orang luka-luka, 916 orang mengungsi, 177 rumah rusak berat, 284 rumah rusak ringan, dan kerusakan lahan seluas $1 \mathrm{~km} 2$. Selain itu, bencana longsor yang terjadi di Kabupaten Bandung Barat memiliki potensi bahaya dengan kelas tinggi seluas 67.920 Ha dan memiliki tingkat kondisi rentan terhadap bencana longsor yang masuk kedalam kelas tinggi pula.

Hal ini didukung dengan data dari Provinsi Jawa Barat Dalam Angka Tahun 2021 yang menyatakan bahwa Kabupaten Bandung Barat berada pada urutan ketiga dengan bencana longsor terbanyak di Jawa Barat yaitu sejumlah 16 kejadian bencana longsor pada Tahun 2020 setelah wilayah Kabupaten Bogor dan Kabupaten Sumedang. Berdasarkan Peraturan Daerah Nomor 2 Tahun 2012 tentang Rencana Tata Ruang Kabupaten Bandung Barat Tahun 20092029, terdapat 9 dari 16 kecamatan yang merupakan wilayah rawan terhadap bencana longsor. Wilayah yang termasuk rawan bencana longsor di Kabupaten Bandung Barat diantaranya Kecamatan Lembang, Kecamatan Parongpong, Kecamatan Cikalongwetan, Kecamatan Cipatat, Kecamatan Cililin, Kecamatan Cipongkor, Kecamatan Sindangkerta, Kecamatan Gununghalu, dan Kecamatan Rongga yang menunjukkan bahwa setengah dari wilayah Kabupaten Bandung Barat merupakan wilayah yang rawan longsor.

Bersinggungan dengan Peraturan Daerah Kabupaten Bandung Barat No. 3 Tahun 2009 Tentang Rencana Pembangunan Jangka Panjang Daerah Tahun 2007-2025, terdapat pembahasan mengenai risiko bencana pergerakan tanah berupa longsoran, rayapan dan longsoran disertai banjir bandang. Tercatat 13 dari 16 kecamatan di Kabupaten Bandung Barat memiliki potensi gerakan tanah menengah hingga tinggi dan kecamatan yang memiliki potensi gerakan tanah menengah hingga tinggi adalah Kecamatan Gununghalu dan Kecamatan Rongga. Kedua kecamatan ini terletak di bagian selatan Kabupaten Bandung Barat. Kabupaten Bandung Barat pun termasuk wilayah yang rawan tanah longsor dalam dokumen Rencana Program Investasi Jangka Menengah (RPIJM) Kabupaten Bandung Barat Tahun 2015-2019.

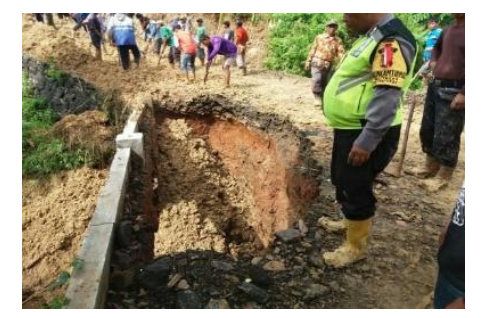

Gambar 1. Dokumentasi Bencana Longsor Tahun 2018

Sumber: BPBD Kabupaten Bandung Barat, 2018

Data yang bersumber dari Open Data Jabar memaparkan dalam kurun waktu 9 tahun sejak Tahun 2012 hingga Tahun 2020 terjadi peningkatan jumlah bencana longsor sebesar 70\% di Kabupaten Bandung Barat dan terdapat variasi peningkatan bencana pada Tahun 2018 Tahun 2020. 


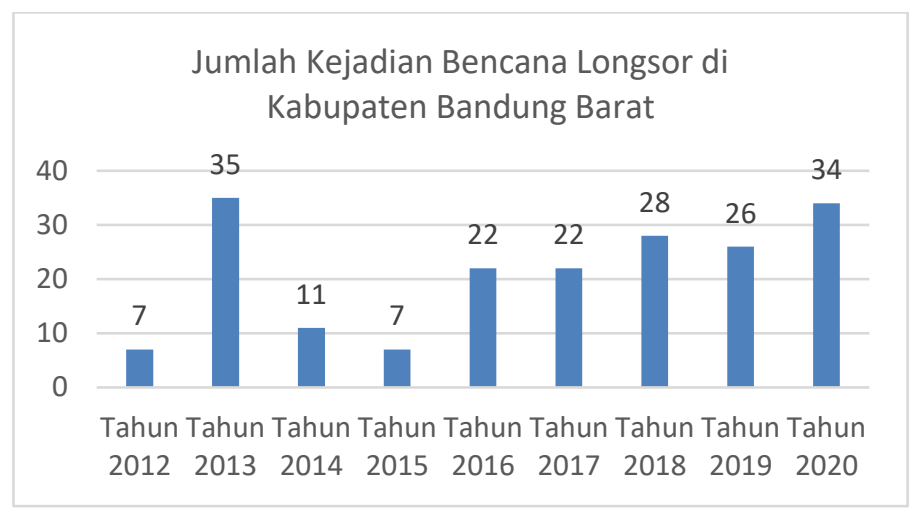

Gambar 2. Grafik Jumlah Bencana Longsor di Kabupaten Bandung Barat Tahun 2012-2020

Sumber: Open Data Jabar, 2021

Dari latar belakang yang telah diuraikan, berdasarkan hal tersebut rumusan masalah penelitian dari Pengaruh Perubahan Curah Hujan dan Perubahan Tutupan Lahan Terhadap Bencana Longsor Berdasarkan Analisis Spasial (Studi Kasus: Kabupaten Bandung Barat) diantaranya sebagai berikut:

1. Bagaimana pengaruh perubahan curah hujan terhadap bencana longsor di Kabupaten Bandung Barat berdasarkan analisis spasial?

2. Bagaimana pengaruh perubahan tutupan lahan terhadap bencana longsor di Kabupaten Bandung Barat berdasarkan analisis spasial?

Tujuan dalam penelitian ini untuk mengkaji tingkat bencana longsor di wilayah Kabupaten Bandung Barat dari pengaruh perubahan curah hujan dan perubahan tutupan lahan berdasarkan analisis spasial agar dapat menghasilkan rekomendasi berupa tindakan pencegahan dan pengendalian untuk meminimalisir dampak kerugian dari bencana longsor yang diakibatkan oleh pengaruh perubahan curah hujan dan perubahan tutupan lahan.

\section{B. Metodologi Penelitian}

Penelitian ini menggunakan pendekatan kuantitatif secara spasial. Pemilihan pendekatan kuantitatif diambil berdasarkan tujuan penelitian dengan menilai pengaruh perubahan curah hujan dan perubahan tutupan lahan terhadap bencana longsor dengan analisis secara spasial. Metode pengumpulan data yang dilakukan dalam penelitian adalah metode pengumpulan data sekunder. Adapun pengumpulan data sekunder yang dilakukan adalah studi literatur dan survei instansional ke instansi-instansi pemerintah sebagai sumber informasi dalam penelitian diantaranya BPBD Kabupaten Bandung BMKG Kota Bandung, BAPPEDA Kabupaten Bandung Barat, dan DLH Kabupaten Bandung Barat. Analisis yang dilakukan dalam penelitian ini adalah analisis klasifikasi tutupan lahan untuk melihat tutupan lahan pada Tahun 2018 Tahun 2020 menggunakan teknik analisis supervised classification dan analisis tingkat bencana longsor dari kondisi eksisting bencana longsor pada Tahun 2018 - Tahun 2020 menggunakan analisis overlay dan skoring pada aplikasi ArcGIS 10.2.

\section{Hasil Penelitian dan Pembahasan}

\section{Curah Hujan Berdasarkan Time Series}

Pada wilayah Kabupaten Bandung Barat berdasarkan data dari Badan Meteorologi Klimatologi dan Geofisika (BMKG) Kota Bandung pada setiap tahunnya terjadi perubahan curah hujan yang dijelaskan dalam Tabel 4.5. Hal ini dapat mewakili curah hujan di wilayah Kabupaten Bandung Barat untuk melihat gambaran curah hujan selama 3 tahun terakhir. 
Tabel 1. Curah HujanTahun 2018-Tahun 2020 Kab. Bandung Barat

\begin{tabular}{|r|l|r|r|r|}
\hline \multirow{2}{*}{ No. } & \multirow{2}{*}{ Bulan } & \multicolumn{3}{|c|}{ Curah Hujan (mm) } \\
\cline { 3 - 5 } & & \multicolumn{1}{|c|}{ Tahun 2018 } & \multicolumn{1}{c|}{ Tahun 2019 } & Tahun 2020 \\
\hline 1 & Januari & 157,7 & 164,3 & 268,2 \\
\hline 2 & Februari & 221,8 & 229,2 & 308,2 \\
\hline 3 & Maret & 187,9 & 260,9 & 344,7 \\
\hline 4 & April & 198,2 & 350,5 & 175 \\
\hline 5 & Mei & 37 & 80,4 & 0 \\
\hline 6 & Juni & 57,1 & 18 & 0 \\
\hline 7 & Juli & 12 & 8,5 & 14,5 \\
\hline 8 & Agustus & 2 & 2,6 & 23,9 \\
\hline 9 & September & 71,3 & 0 & 55,8 \\
\hline 10 & Oktober & 101,8 & 0 & 270 \\
\hline 11 & November & 284,1 & 274,9 & 158 \\
\hline 12 & Desember & 151,1 & 0 & 256 \\
\hline JUMLAH & $\mathbf{1 . 4 8 2}$ & $\mathbf{1 . 3 8 9 , 3}$ & $\mathbf{1 . 8 7 4 , 3}$ \\
\hline RATA-RATA & $\mathbf{1 2 3 , 5}$ & $\mathbf{1 1 5 , 8}$ & $\mathbf{1 5 6 , 2}$ \\
\hline
\end{tabular}

Sumber: Badan Meteorologi Klimatologi dan Geofisika Kota Bandung, 2021

\section{Analisis Klasifikasi Tutupan Lahan}

Pada tutupan lahan RTRW Kab. Bandung Barat terdapat luas kawasan terbangun sebesar $15,19 \%$ dan kawasan non terbangun sebesar $84,81 \%$ dari total wilayah Kabupaten Bandung Barat. Jika dibandingkan dengan tutupan lahan berdasarkan kondisi eksisting Tahun 2018Tahun 2020 terdapat kawasan terbangun sebesar 37,14\% pada Tahun 2018, kemudian meningkat sebesar 38,44\% pada Tahun 2019, dan sedikit menurun pada Tahun 2020 38,33\% dari total luas wilayah Kab. Bandung Barat . Untuk Kawasan non terbangun terdapat luas wilayah pada Tahun 2018 sebesar 62,86\%, kemudian menurun pada tahun 2019 sebesar $61,56 \%$, dan pada Tahun 2020 sedikit meningkat sebesar dari total luas wilayah Kab. Bandung Barat.

Maka dari itu didapatkan hasil selisih luas wilayah sekitar 22\%-23\% dari tutupan lahan berdasarkan data RTRW Kabupaten Bandung Barat dengan tutupan lahan eksisting Tahun 2018 - Tahun 2020. Pada kawasan terbangun, luas tutupan lahan eksisting lebih besar dibandingkan dengan luas tutupan lahan berdasarkan RTRW Kabupaten Bandung Barat sehingga terjadi peningkatan luas wilayah di kawasan terbangun sebesar 22\%-23\%. Pada kawasan non terbangun, luas tutupan lahan eksisting lebih kecil dibandingkan dengan luas tutupan lahan berdasarkan RTRW Kabupaten Bandung Barat sehingga terjadi penurunan luas wilayah pada kawasan non terbangun sebesar 22\%-23\%. Dari hasil analisis tersebut dapat disimpulkan bahwa terjadi peningkatan jumlah dan kegiatan masyarakat di Kabupaten Bandung Barat dengan ditandai dengan meningkatnya kawasan terbangun di Kabupaten Bandung Barat.

\section{Analisis Tingkat Bencana Tanah Longsor Tahun 2018-2020}

Analisis bencana tanah longsor merupakan analisis yang digunakan untuk melihat pengaruh perubahan curah hujan dan perubahan tutupan lahan terhadap bencana longsor sesuai dengan kondisi eksisting pada Tahun 2018-Tahun 2020.

\section{Tingkat Bencana Longsor Tahun 2018}

Hasil analisis menunjukkan terdapat tingkat bencana longsor sedang yang mendominasi wilayah Kabupaten Bandung Barat Tahun 2018 dengan luas sebesar 96.660,06 Ha atau 75,53\% dari wilayah Kabupaten Bandung Barat. Hal ini dikarenakan pengaruh dari variabel curah hujan sebesar $1.482 \mathrm{~mm} /$ tahun. Dalam Tahun 2018 sudah terjadi longsor sebanyak 150 kali dalam setahun di 61 desa di Kabupaten Bandung Barat dan wilayah kecamatan yang paling banyak mengalami bencana longsor terdapat di Kecamatan Cipatat dengan bencana longsor sebanyak 22 kali dalam setahun. 
Tabel 2. Tingkat Bencana Longsor di Kab. Bandung Barat Tahun 2018

\begin{tabular}{|c|c|r|r|}
\hline No. & Tingkat Bencana Longsor & \multicolumn{1}{|c|}{ Luas (Ha) } & \multicolumn{1}{|c|}{ Presentase (\%) } \\
\hline 1 & Rendah & $31.309,90$ & 24,47 \\
\hline 2 & Sedang & $96.660,06$ & 75,53 \\
\hline & JUMLAH & $\mathbf{1 2 7 . 9 7 0}$ & $\mathbf{1 0 0}$ \\
\hline
\end{tabular}

Sumber: Hasil Analisis, 2021

Untuk mengetahui tingkat bencana longsor di Kabupaten Bandung Barat pada Tahun 2018 dapat dilihat dalam peta tingkat bencana longsor di Kabupaten Bandung Barat pada Tahun 2018 di Gambar 3. dan keterangan lebih detail diuraikan dalam Tabel 2. mengenai luas tingkat bencana longsor di Kabupaten Bandung Barat Tahun 2018.
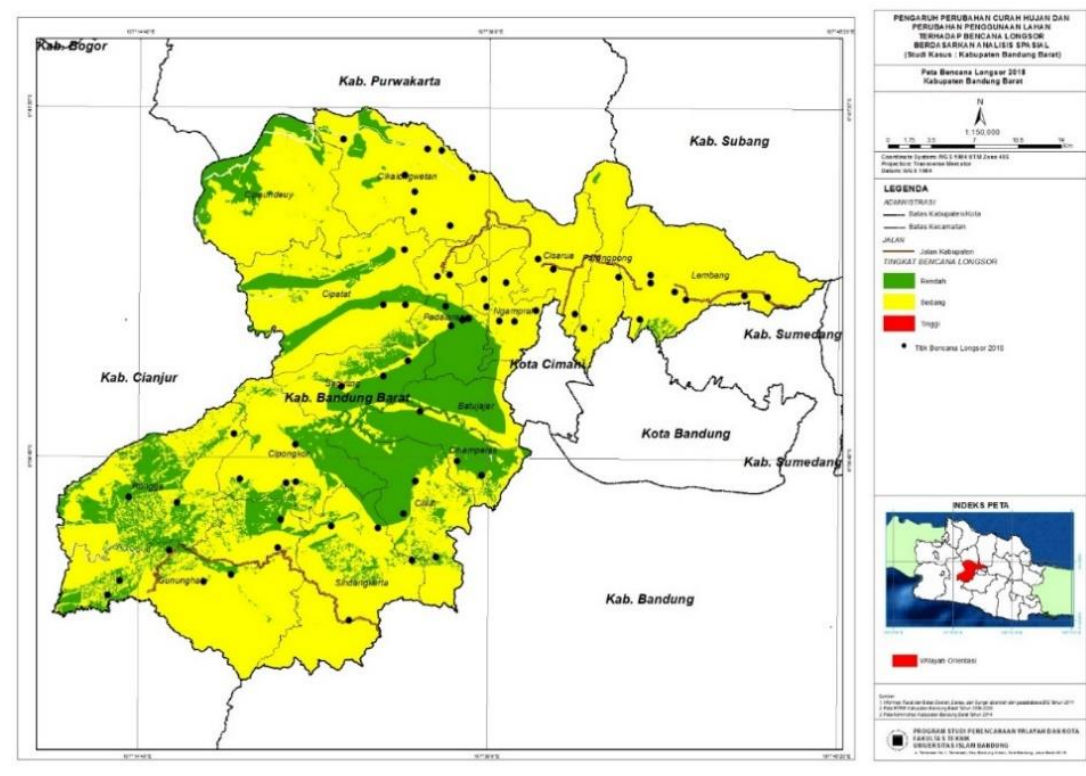

Gambar 3. Peta Tingkat Bencana Longsor 2018

\section{Tingkat Bencana Longsor Tahun 2019}

Hasil analisis menunjukkan terdapat tingkat bencana longsor sedang yang mendominasi wilayah Kabupaten Bandung Barat Tahun 2019 dengan luas sebesar 96.091,22 Ha atau 75,16\% dari wilayah Kabupaten Bandung Barat. Hal ini dikarenakan pengaruh dari variabel curah hujan sebesar 1.389,3 mm/tahun sehingga wilayah Kabupaten Bandung Barat memiliki potensi longsor sedang. Pada Tahun 2019 sudah terjadi longsor sebanyak 152 kali dalam setahun pada 53 desa di Kabupaten Bandung Barat dan wilayah kecamatan yang paling banyak mengalami bencana longsor terdapat di Kecamatan Cililin karena telah terjadi bencana longsor sebanyak 46 kali dalam setahun.

Tabel 3. Tingkat Bencana Longsor di Kabupaten Bandung Barat Tahun 2019

\begin{tabular}{|l|l|r|r|}
\hline No. & \multicolumn{1}{|c|}{ Tingkat Bencana Longsor } & Luas (Ha) & \multicolumn{1}{c|}{ Presentase (\%) } \\
\hline 1 & Rendah & $31.752,25$ & 24,84 \\
\hline 2 & Sedang & $96.091,22$ & 75,16 \\
\hline \multicolumn{2}{|c|}{ JUMLAH } & $\mathbf{1 2 7 . 8 4 3}$ & $\mathbf{1 0 0}$ \\
\hline
\end{tabular}

Sumber: Hasil Analisis, 2021

Untuk mengetahui tingkat bencana longsor di Kabupaten Bandung Barat pada Tahun 2019 dapat dilihat dalam peta tingkat bencana longsor di Kabupaten Bandung Barat pada Tahun 2019 di Gambar 4. dan keterangan lebih detail diuraikan dalam Tabel 3. mengenai luas tingkat bencana longsor di Kabupaten Bandung Barat Tahun 2019. 

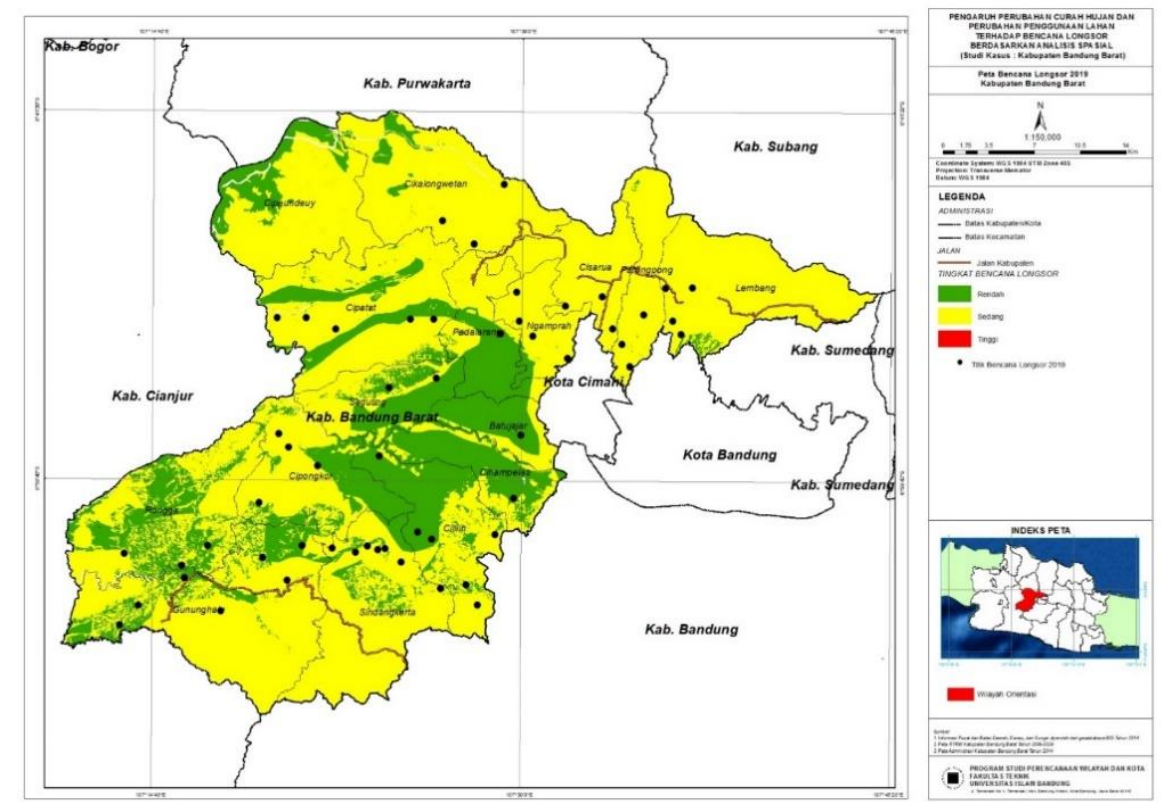

Gambar 4. Peta Tingkat Bencana Longsor 2019

\section{Tingkat Bencana Longsor Tahun 2020}

Hasil analisis menunjukkan terdapat tingkat bencana longsor sedang yang mendominasi wilayah Kabupaten Bandung Barat dengan luas sebesar 108.381,46 Ha atau 84,69\% dari wilayah Kabupaten Bandung Barat. Hal ini dikarenakan pengaruh dari variabel curah hujan sebesar $1.874,3 \mathrm{~mm}$ /tahun sehingga wilayah Kabupaten Bandung Barat memiliki potensi longsor sedang. Pada Tahun 2020 sudah terjadi longsor sebanyak 144 kali dalam setahun di 67 desa di Kabupaten Bandung Barat dan wilayah kecamatan yang paling banyak mengalami bencana longsor terdapat di Kecamatan Ngamprah karena telah terjadi bencana longsor sebanyak 34 kali dalam setahun.

Tabel 4. Tingkat Bencana Longsor di Kabupaten Bandung Barat Tahun 2020

\begin{tabular}{|c|l|r|r|}
\hline No. & \multicolumn{1}{|c|}{ Tingkat Bencana Longsor } & \multicolumn{1}{c|}{ Luas (Ha) } & \multicolumn{1}{c|}{ Presentase (\%) } \\
\hline 1 & Rendah & $15.280,42$ & 11,94 \\
\hline 2 & Sedang & $108.381,46$ & 84,69 \\
\hline 3 & Tinggi & $4.308,11$ & 3,37 \\
\hline \multicolumn{2}{|c|}{ JUMLAH } & $\mathbf{1 2 7 . 9 7 0}$ & $\mathbf{1 0 0}$ \\
\hline
\end{tabular}

Sumber: Hasil Analisis, 2021

Untuk mengetahui tingkat bencana longsor di Kabupaten Bandung Barat pada Tahun 2020 dapat dilihat dalam peta tingkat bencana longsor di Kabupaten Bandung Barat pada Tahun 2020 di Gambar 5. dan keterangan lebih detail diuraikan dalam Tabel 4. mengenai luas tingkat bencana longsor di Kabupaten Bandung Barat Tahun 2020. 

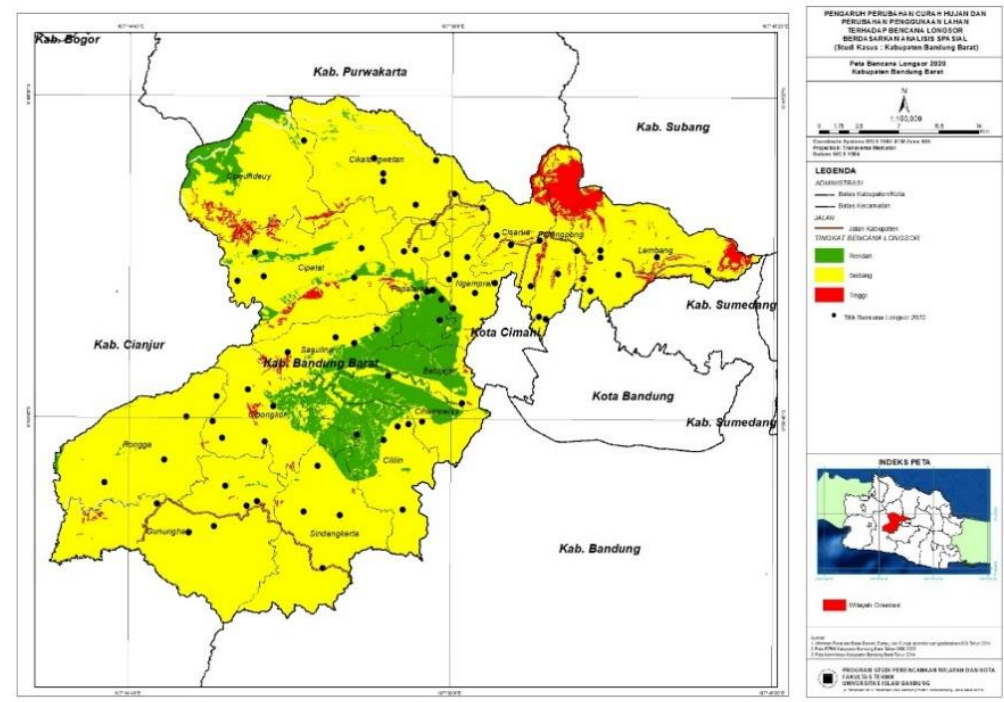

Gambar 5. Peta Tingkat Bencana Longsor 2020

\section{Kesimpulan}

Hasil studi yang telah dianalisa dapat disimpulkan bahwa pada kawasan terbangun, luas tutupan lahan eksisting lebih besar dibandingkan dengan luas tutupan lahan berdasarkan RTRW Kabupaten Bandung Barat sehingga terjadi peningkatan luas wilayah di kawasan terbangun sebesar 22\%-23\%. Pada kawasan non terbangun, luas tutupan lahan eksisting lebih kecil dibandingkan dengan luas tutupan lahan berdasarkan RTRW Kabupaten Bandung Barat sehingga terjadi penurunan luas wilayah pada kawasan non terbangun sebesar 22\%-23\%. Terjadi peningkatan jumlah dan kegiatan masyarakat di Kabupaten Bandung Barat dengan ditandai dengan meningkatnya kawasan terbangun di Kabupaten Bandung Barat. Sementara itu, pada grafik curah hujan yang didapatkan secara time series dari Tahun 2018-Tahun 2020 menunjukkan bahwa terjadi penurunan dari $1.482 \mathrm{~mm} /$ tahun menjadi $1.389,3 \mathrm{~mm} / \mathrm{tahun}$ dan pada Tahun 2020 kembali meningkat sebanyak $485 \mathrm{~mm} /$ tahun menjadi 1.874,3 mm/tahun.

Oleh karena itu, setelah dilakukan penelitian tingkat bencana lonsor dari tutupan lahan dan curah hujan Tahun 2018-Tahun 2020 dengan teknik analisis overlay didapatkan bahwa pada Tahun 2018 tingkat bencana longsor dengan tingkat rendah sebesar 31.309,90 $\mathrm{Ha}$ atau 24,47\% dan tingkat sedang sebesar 96.660,06 Ha atau 75,53\% dengan jumlah longsor sebanyak 150 kali pada 61 desa di Kabupaten Bandung Barat. Kemudian, pada Tahun 2019 tingkat bencana longsor yang terjadi memiliki tingkat rendah sebesar 31.752,25 $\mathrm{Ha}$ atau 24,84\% dan tingkat sedang sebesar $96.091,22 \mathrm{Ha}$ atau 75,16\% dengan jumlah longsor sebanyak 152 kali pada 53 desa di Kabupaten Bandung Barat. Terakhir, pada Tahun 2020 tingkat bencana longsor memiliki tingkat rendah sebesar 15.280,42 $\mathrm{Ha}$ atau 11,94\%, tingkat sedang sebesar 108.381,46 Ha atau $84,69 \%$, dan tingkat tinggi sebesar 4.308,11 Ha atau 3,37\% dengan jumlah longsor sebanyak 144 kali pada 67 desa di Kabupaten Bandung Barat. Dari hasil analisis ini menunjukkan tingkat bencana longsor dari pengaruh perubahan curah hujan dan tutupan lahan mempengaruhi jumlah wilayah yang terkena bencana longsor, tetapi bertolak belakang dengan jumlah kejadian longsor yang justru meningkat pada Tahun 2019. Rekomendasi yang dapat diberikan adalah

1. Menambahkan kawasan rawan bencana longsor pada RTRW Kabupaten Bandung Barat.

2. Melakukan pengendalian RTRW secara berkala agar dapat dievaluasi penggunaan lahan eksisting terutama pada wilayah yang memiliki tingkat bencana longsor yang sedang dan tinggi.

3. Menambahkan jalur evakuasi longsor di Kabupaten Bandung Barat.

4. Mengembangkan alat yang dapat memonitor pergerakan longsor sebagai pencegahan timbulnya bencana longsor dengan mendeteksi jumlah curah hujan yang turun di Kabupaten Bandung Barat. 


\section{Acknowledge}

Penulis mengucapkan terimakasih kepada ibu DR. Yulia Asyiawati, ST., M. Si dan Bapak DR. Dudi Nasrudin Usman, Ir, M.T., selaku dosen pembimbing yang telah memberikan bimbingan dan saran kepada penulis selama pelaksanaan dan penulis artikel ini.

\section{Daftar Pustaka}

[1] Annisa, J., Sutikno, S., \& Rinaldi. (2015). Analisis Daerah Rawan Longsor Berbasis Sistem Informasi Geografis (Studi Kasus Kabupaten Lima Puluh Kota, Sumatera Barat).

[2] Febrianti, N. (2009). Analisis dampak perubahan curah hujan terhadap tanah longsor di Jawa Barat. Seminar Nasional "Proyeksi Iklim Dan Kualitas Udara 2010-2014" 1 (LAPAN), July 2009, 91-100.

[3] Hardianto, A., Winardi, D., Rusdiana, D. D., Putri, A. C. E., Ananda, F., Devitasari, Djarwoatmodjo, F. S., Yustika, F., \& Gustav, F. (2020). Pemanfaatan Informasi Spasial Berbasis SIG untuk Pemetaan Tingkat Kerawanan Longsor di Kabupaten Bandung Barat, Jawa Barat. Jurnal Geosains Dan Remote Sensing, 1(1), 23-31. https://doi.org/10.23960/jgrs.2020.v1i1.16

[4] Hermon, D. (2012). Mitigasi Bencana Hidrometeorologi. Kementrian Pekerjaan Umum dan Perumahan Rakyat. (2017). Modul Geologi dan Hidrogeologi Pelatihan Perencanaan Air Tanah 2017. In Pusat Pendidikan dan Pelatihan Sumber Daya Air dan Konstruksi.

[5] Khoiriyah, T. M., Feranie, S., \& Tohari, A. (2016). Studi Parametrik Pengaruh Pola Curah Hujan Terhadap Jarak Jangkauan (Run-Out) Longsor Di Lembang-Bandung. Spektra: Jurnal Fisika Dan Aplikasinya, 1(2), 129-136. https://doi.org/10.21009/spektra.012.06

[6] Lili Somantri. (n.d.). Kajian Mitigasi Bencana Longsor Lahan Dengan Menggunakan Teknologi Penginderaan Jauh.

[7] Mala, B. K. S., Moniaga, I. L., \& Karongkong, H. H. (2016). Perubahan Tutupan Lahan Terhadap Potensi Bahaya Longsor Dengan Pendekatan Sistem Informasi Geografis Di Kolonodale Kabupaten Morowali Utara.

[8] Nandi. (2007). Longsor.

[9] Nugroho, D. D., \& Nugroho, H. (2020). Analisis Kerentanan Tanah Longsor Menggunakan Metode Frequency Ratio di Kabupaten Bandung Barat, Jawa Barat. Geoid, 16(1), 8. https://doi.org/10.12962/j24423998.v16i1.7680

[10] Ramadhan, R., Widiatmaka, W., \& Sudadi, U. (2016). Perubahan Penggunaan Lahan Dan Pemanfaatan Ruang Pada Wilayah Rawan Longsor Di Kabupaten Banjarnegara, Jawa Tengah (Land Use Change and Spatial Utilization in Landslide Vulnerable Regions of Banjarnegara Regency, Central Java). Jurnal Pengelolaan Sumberdaya Alam Dan Lingkungan, 6(2), 159-167.

[11] Rupaka, A. P. G., Suharyanto, \& Sudarno. (2015). Analisis Kesesuaian Penggunaan Lahan Pada Daerah Rawan Tanah Longsor Di Kabupaten Tegal. Jurnal Presipitasi, 12(2), 5256.

[12] Soewandita, H. (2018). Analisis Kawasan Rawan Longsor Dan Keterkaitannya Terhadap Kualitas Tanah Dan Penggunaan Lahan (Kasus Di Kawasan Agribisnis Juhut Kabupaten Pandeglang). Jurnal Alami: Jurnal Teknologi Reduksi Risiko Bencana, 2(1), 27. https://doi.org/10.29122/alami.v2i1.2826

[13] Taufik, D. I. M., Kurniawan, A., \& Putri, A. R. (2016). Identifikasi Daerah Rawan Tanah Longsor Menggunakan SIG (Sistem Informasi Geografis). 5(2).

[14] Tejakusuma, I. G. (2017). Interaksi Faktor Yang Mempengaruhi Longsor Jati Radio. Jurnal Sains Dan Teknologi Mitigasi Bencana, 12(1).

[15] Warnadi. (2014). Inventarisasi Daerah Rawan Longsor Kabupaten Banjarnegara Jawa Tengah. SPATIAL Wahana Komunikasi Dan Informasi Geografi, 12(2). 